\title{
Allergy Immunotherapy as an Early Intervention in Patients with Child-Onset Atopic Asthma
}

\author{
Hiroshi Nagaya $^{a}$ Stephen Maren $^{b}$ Naomi Nagaya ${ }^{c}$ \\ ${ }^{a}$ Department of Allergy, Kugayama Hospital, Tokyo, Japan; Departments of ${ }^{b}$ Psychology and Neuroscience \\ Program, and ${ }^{\mathrm{C}}$ Department of Molecular, Cellular and Developmental Biology, University of Michigan, \\ Ann Arbor, Mich., USA
}

\section{Key Words}

Allergy immunotherapy · Asthma · Forced expiratory volume in $1 \mathrm{~s}$

\begin{abstract}
Background: In patients with bronchial asthma an effective treatment is required at early stages of the disease to prevent irreversible structural changes of the airways. The objective of this study was to evaluate the beneficial effects of our routine immunotherapy as an early intervention on $\mathrm{FEV}_{1}$ in patients with child-onset atopic asthma. Methods: Beneficial effects of successful immunotherapy on $\mathrm{FEV}_{1}$ were analyzed retrospectively in 43 unselected patients who received our routine standard subcutaneous immunotherapy with periodic $\mathrm{FEV}_{1}$ measurements and became asymptomatic. Results: Although there was no significant correlation between the duration of asthma symptoms prior to immunotherapy and the changes in $\mathrm{FEV}_{1}$ before and after immunotherapy in 43 unselected patients, there was a significant inverse correlation between these two parameters in 23 patients whose asthma duration was less than 20 years.

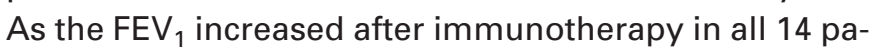
tients whose asthma duration was less than 5 years, the 43 patients were divided into a group 1 including these 14 patients and a group 2 including 29 patients whose asthma duration was more than 5 years. The FEV ${ }_{1}$ de-
\end{abstract}

\section{KARGER}

Fax +4161306 1234 E-Mail karger@karger.ch www.karger.com (c) 2006 S. Karger AG, Basel

1018-2438/06/1391-0009\$23.50/0

Accessible online at: www.karger.com/iaa creased in 7 of the 29 asymptomatic patients in group 2. There was no difference in the initial $\mathrm{FEV}_{1}$ between the two groups, but the final $\mathrm{FEV}_{1}$ and the mean of the average increase in $\mathrm{FEV}_{1}$ per year by immunotherapy were significantly higher in group 1 than in group 2. Conclusions: Immunotherapy should be started as early as possible at the youngest age in order to increase a beneficial effect of successful immunotherapy on $\mathrm{FEV}_{1}$ improvement.

Copyright @ 2006 S. Karger AG, Basel

\section{Introduction}

Allergy immunotherapy (AI) and allergen avoidance are the only treatments that can change the natural course of allergic rhinitis and atopic asthma [1]. In the last 90 years many studies, including double-blind controlled studies, have proved the efficacy of AI and suggest that it prevents the development of bronchial asthma in patients with allergic rhinitis [1-4].

Although asthma attacks may be transient and clinically self-limited, it has been well established that recurrent allergic inflammation in the bronchial tissues can cause irreversible structural changes with the potential to progress into chronic obstructive pulmonary insufficiency [5]. AI is indicated when avoidance of specific allergens and symptomatic medications fail to relieve the allergy

Correspondence to: Dr. Hiroshi Nagaya

Department of Allergy, Kugayama Hospital

2-14-20 Kita-karasuyama

Tokyo, Setagaya-ku 157-0061 (Japan)

Tel. +8133309 1111, Fax +81333261980 
symptoms [1]. However, it may be necessary to initiate an allergen-specific prophylactic treatment against unavoidable allergens in the earliest possible stage of the disease in order to prevent any structural damage in the airways [4, 6].

Forced expiratory volume in $1 \mathrm{~s}\left(\mathrm{FEV}_{1}\right)$ is less variable and, therefore, more useful than peak expiratory flow in predicting the prognosis of bronchial asthma $[7,8]$. Inhaled corticosteroids (ICS) are very effective in achieving high $\mathrm{FEV}_{1}$ if introduced soon after the onset of bronchial asthma as a first-line prophylactic treatment $[9,10]$. However, in young children ICS may not reach the peripheral airways due to small airway diameters [11] and they have potential side effects on growth and development [12]. Furthermore, asthma exacerbated with declining FEV $_{1}$ within 1 year when ICS had been discontinued [13].

Our primary purpose in this study was to examine whether AI that we use routinely in our clinic is truly beneficial for every patient who improves as assessed by the criteria of the 1997 NIH guidelines' classification of clinical symptoms [5]. This study was prompted by our daily observation that $\mathrm{FEV}_{1}$ in relatively old patients who had had child-onset atopic asthma for longer periods of time did not improve as well as in younger patients even though clinically they were just as asymptomatic as younger patients. Beneficial effects of successful immunotherapy on $\mathrm{FEV}_{1}$ improvements were analyzed retrospectively and evaluated whether or not the beneficial effects are influenced by the duration of asthma symptoms prior to immunotherapy.

\section{Material and Methods}

\section{Patients}

A total of 43 patients with child-onset atopic asthma who had been followed prospectively with regular immunotherapy injections and periodic $\mathrm{FEV}_{1}$ measurements at the Allergy Clinic of Kugayama Hospital for 1-11 years and became asymptomatic were the subjects of this study. Patients who did not become asymptomatic over the course of immunotherapy were not included in the study. Immunotherapy in this population may not have been optimal because of a suboptimal selection of allergens for immunotherapy and/or insufficient allergen doses. In order to avoid a bias as to who should or should not be on immunotherapy, we tried to place every patient with child-onset atopic asthma on immunotherapy as early as possible. At the beginning of immunotherapy in the study population, the ages of the patients ranged from 4 to 65 years and there were 23 males and 20 females. This study was exempt from a review of the ethical standards of the hospital since we planned to treat the study patients like any other patients attending the clinic without requiring extra procedures or medications.

\section{Onset and Duration of Asthma Symptoms}

Each patient developed atopic asthma before the age of 15 and had the asthma severity classification of 'mild persistent' or greater just prior to starting immunotherapy. Patients who had been diagnosed to have bronchial asthma prior to age 15 but were in remission for varying periods of time were considered to have developed asthma at the time of the initial diagnosis. Patients who coughed with wheezing and dyspnea when they had exacerbations of allergic rhinitis or respiratory tract infection without being diagnosed to have asthma were considered to have developed asthma at the time of onset of first asthma-like symptoms if they were diagnosed to have asthma later.

\section{Allergy Test}

Patients were prick-tested against 60 inhalant allergens and blood samples were tested with radioallergosorbent test (RAST) against at least 10 inhalant allergens including Dermatophagoides farinae and Dermatophagoides pteronyssinus, cat, dog and cockroach. Patients were considered to have atopic asthma if they showed 3 or $4+$ prick test reactions or positive RAST against at least one of the following allergens including D. farinae, D. pteronyssinus, cat, dog, cockroach, Alternaria, Cladosporium, Cephalosporium, Fusarium or two or more common ragweeds or grasses with the methods described previously [14]. In addition, many patients including some children at the age of 4 or 5 were reactive against multiple other pollens and fungi and their total serum IgE levels and peripheral blood eosinophil counts (\%) were also elevated.

\section{Lung Function}

Pulmonary function tests were performed using a $10 \mathrm{~L}$ Chestac33 rolling-seal-type spirometer (Chest MI, Tokyo, Japan). FEV values were expressed as percentages of predicted vital capacity $\left(\mathrm{VC}_{\mathrm{p}}\right), \mathrm{FEV}_{1} / \mathrm{VC}_{\mathrm{p}} \times 100(\%)$. $\mathrm{FEV}_{1}$ was measured prior to immunotherapy and periodically as needed thereafter usually once or twice a year in stable respiratory conditions. Changes in $\mathrm{FEV}_{1}$ values were evaluated by averaging the differences between the initial and final values per year of immunotherapy.

\section{Allergy Immunotherapy}

Immunotherapy was performed with conventional standard subcutaneous methods [15]. Selection of allergens for immunotherapy was based on prick test and RAST reactions of individual patients and their clinical relevance as causes of respiratory symptoms. Allergen solutions were purchased from Hollister-Stier Laboratories (Spokane, Wash., USA) including standardized mite, cat, grass, short ragweed and other nonstandardized allergen extracts. Although the major allergens for immunotherapy were mite or cat or both, common nonstandardized allergens, such as dog, cockroach, birch, cypress, alder, sagebrush, plantain pollens or Alternaria were also included in the immunotherapy under our routine clinical settings. Standardized Japanese cedar (Cryptomeria japonica) pollen solutions were purchased from Torii, Tokyo, Japan. The highest dose per injection for standardized allergens were approximately 600 allergy units of $D$. farinae and $D$. pteronyssinus mixture $(1.5 \mu \mathrm{g}$ of Der f 1 and $3.0 \mu \mathrm{g}$ of Der p 1), 2,000 bioequivalent allergy units (BAU) of timothy grass (7 $\mu \mathrm{g}$ of Phl p 5), 1,000 BAU of cat ( $6 \mu \mathrm{g}$ of Fel d 1), $4 \mu \mathrm{g}$ of short ragweed (Amb a 1) and $1.25 \mu \mathrm{g}$ of Japanese cedar (Cry j 1), respectively. The frequency of immunotherapy injections varied from 2-3 times a week to once every 2-4 weeks depending on the stage of immunotherapy. 


\section{Medications}

At their initial visits patients were prescribed inhalation of $\beta_{2^{-}}$ agonists and corticosteroids and oral theophylline. Every patient was maintained on ICS even after they became asymptomatic unless their $\mathrm{FEV}_{1} / \mathrm{VC}_{\mathrm{p}}$ exceeded $100 \%$. Administration of $\beta_{2}$-agonists and theophylline was determined by their symptomatology. $\mathrm{Pa}-$ tients who were on oral corticosteroids prior to immunotherapy or who needed short courses of oral steroids during immunotherapy were eventually able to discontinue oral steroids completely on immunotherapy. In order to minimize the effect of oral steroids on $\mathrm{FEV}_{1}$, the final $\mathrm{FEV}_{1}$ values were obtained at least 1 year after the last dose of oral steroids.

\section{Asthma Severity}

The severity of asthma was graded according to the classification of the NIH guidelines of 1997 [5]. Since one of the purposes of this study was to evaluate whether or not an early intervention with successful immunotherapy was effective in improving $\mathrm{FEV}_{1}$, it was necessary for every patient included in this study to have improved more than the criteria for 'mild intermittent' classification in clinical symptoms. Therefore, all 43 patients were practically asymptomatic having had only transient mild wheezing less than once in 3 months with no night symptoms. In an attempt to assess whether the severity of asthma prior to immunotherapy had any effect on improvement of $\mathrm{FEV}_{1}$, we assigned a severity of 1 through 4 to mild intermittent, mild persistent, moderate persistent and severe persistent classes, respectively.

\section{Statistical Analysis}

The correlation between the duration of asthma prior to immunotherapy and the changes in $\mathrm{FEV}_{1}$ after immunotherapy was evaluated by the Spearman correlation coefficient. Total serum IgE levels and peripheral blood eosinophil counts (\%) were analyzed with unpaired $t$ tests (two tailed). Lung function data (initial and final $\mathrm{FEV}_{1} / \mathrm{VC}_{\mathrm{p}} \%$ ) were analyzed using a repeated measures analysis of variance (ANOVA) with variables of group (group 1 vs. group 2) and time (initial vs. final). Planned comparisons $(\mathrm{p}<0.05)$ in the form of unpaired $t$ tests were used for pairwise comparisons of the means after a significant omnibus $F$ ratio in the ANOVA. The asthma severity scores were analyzed with a nonparametric Mann-Whitney U test (for all statistical tests: $\alpha=0.05$ ).

\section{Results}

Initially, we tried to correlate the duration of asthma symptoms prior to immunotherapy with the changes in $\mathrm{FEV}_{1} / \mathrm{VC}_{\mathrm{p}}(\%)$ per year before and after immunotherapy in all 43 patients. As shown in figure 1, there was no significant correlation between these two parameters (correlation coefficient -0.26 with $\mathrm{p}=0.09$ ). There was 1 patient with an asthma duration of 30 years whose $\mathrm{FEV}_{1}$ changed $23.3 \%$ per year by immunotherapy. This patient's exceptionally large change in $\mathrm{FEV}_{1}$ was approximately 4 times the standard deviation of the mean change in $\mathrm{FEV}_{1}$ of 43 patients. When this patient was excluded, the correlation

AI as Early Intervention in Child-Onset Atopic Asthma

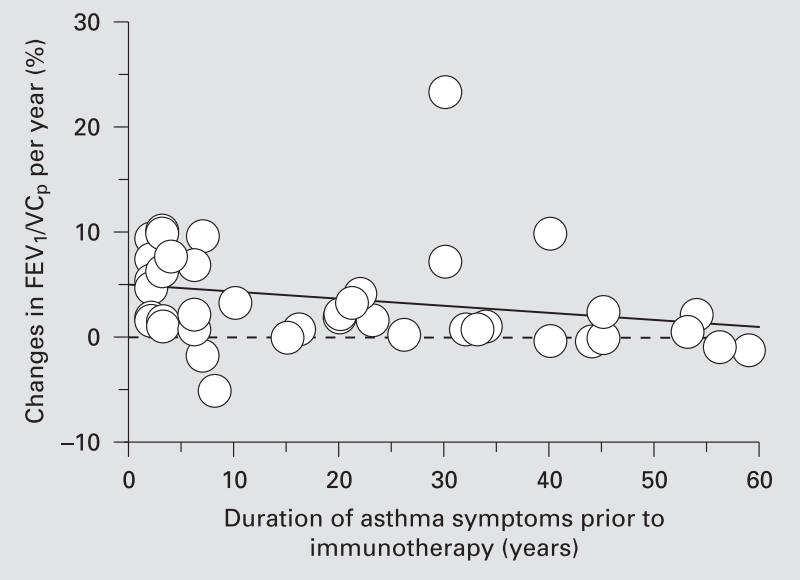

Fig. 1. Correlation between the changes in $\mathrm{FEV}_{1} / \mathrm{VC}_{\mathrm{p}} \times 100(\%)$ per year by immunotherapy and the duration of asthma prior to immunotherapy in 43 patients.

coefficient was -0.42 with $p=0.006$. The regression line for the 42 patients was almost identical to that for all 43 patients (not shown). It appears, therefore, that there might be a trend towards a significant correlation between the asthma duration prior to immunotherapy and the changes in $\mathrm{FEV}_{1}$ after immunotherapy. Indeed, there was a significant correlation (correlation coefficient -0.493 with $\mathrm{p}<0.02$ ) between these two parameters in 23 patients whose asthma duration was less than 20 years. In figure 1 , it was noted that every patient whose asthma duration was less than 5 years showed an increase in $\mathrm{FEV}_{1} / \mathrm{VC}_{\mathrm{p}}(\%)$ after immunotherapy. Accordingly, 43 patients were divided into a group 1 including 14 patients who began immunotherapy less than 5 years after the onset of the first asthma symptoms and a group 2 including 29 patients who began immunotherapy more than 5 years after the onset of the first asthma symptoms. In group 1, the severity of asthma prior to immunotherapy was mild persistent in 1 , moderate persistent in 4 and severe persistent in 9 patients. In group 2, 5 patients had mild persistent, 9 had moderate persistent and 15 had severe persistent asthma prior to immunotherapy. Table 1 shows that there were no significant differences in total serum IgE levels, peripheral blood eosinophil counts or the severity of asthma prior to immunotherapy between groups 1 and 2 . The mean age at which immunotherapy was begun was significantly younger in group 1 than in group 2.

In all 14 patients in group 1 and 28 of 29 patients in group 2, the major allergens for immunotherapy were

Int Arch Allergy Immunol 2006;139:9-15 


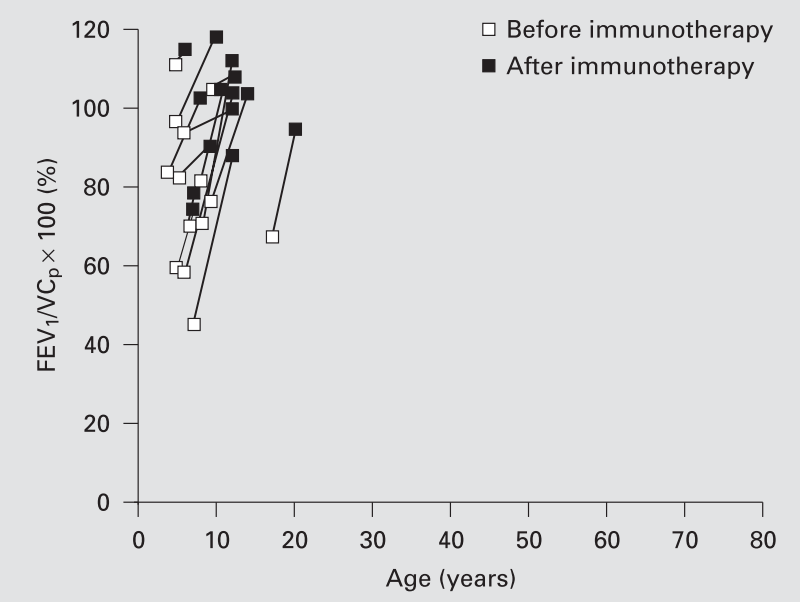

Fig. 2. The 14 patients in group 1 began immunotherapy less than 5 years after the onset of their first asthma symptoms.

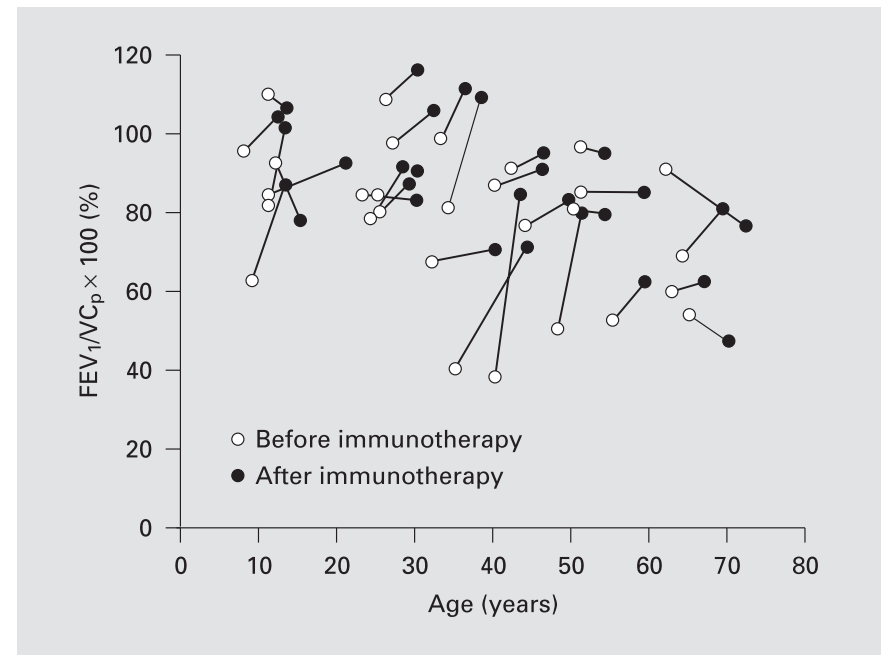

Fig. 3. The 29 patients in group 2 began immunotherapy more than 5 years after the onset of their first asthma symptoms.

Table 1. Comparison of clinical backgrounds between groups 1 and 2

\begin{tabular}{|c|c|c|c|}
\hline & Group 1 & Group 2 & $\mathrm{p}$ values \\
\hline Patients & 14 & 29 & \\
\hline $\begin{array}{l}\text { Duration of asthma symptoms prior to immunotherapy, } \\
\text { years }\end{array}$ & $<5$ & $>5$ & \\
\hline Age when immunotherapy was begun, years & $7.214 \pm 0.866$ & $35.207 \pm 3.334$ & $<0.0001$ \\
\hline Total serum IgE, IU/ml & $728.357 \pm 156.411$ & $605.655 \pm 132.835$ & 0.5805 \\
\hline Blood eosinophils, $\%$ & $9.929 \pm 1.252$ & $8.207 \pm 0.974$ & 0.3031 \\
\hline Asthma severity prior to immunotherapy, arbitrary units & $3.571 \pm 0.173$ & $3.345 \pm 0.143$ & 0.4217 \\
\hline
\end{tabular}

Values represent mean \pm standard error of the mean.

D. farinae and D. pteronyssinus. In the remaining 1 patient in group 2, the major allergen was cat. Nine of the 28 patients in group 2 who were allergic to mites were also allergic to cats.

Figure 2 shows the initial and final $\mathrm{FEV}_{1} / \mathrm{VC}_{\mathrm{p}} \%$ of the 14 patients in group 1 . The $\mathrm{FEV}_{1} / \mathrm{VC}_{\mathrm{p}} \%$ increased in every patient. Figure 3 shows the initial and final $\mathrm{FEV}_{1} /$ $\mathrm{VC}_{\mathrm{p}} \%$ of the 29 patients in group 2. The $\mathrm{FEV}_{1} / \mathrm{VC}_{\mathrm{p}} \%$ increased in 21 patients, decreased in 7 patients and was unchanged in 1 of the 29 patients. Figure 4 shows average changes in $\mathrm{FEV}_{1} / \mathrm{VC}_{\mathrm{p}} \%$ per year by immunotherapy. Table 2 shows that there was no significant difference in the mean $\mathrm{FEV}_{1} / \mathrm{VC}_{\mathrm{p}} \%$ before immunotherapy between groups 1 and 2. After immunotherapy the mean $\mathrm{FEV}_{1} /$ $\mathrm{VC} \%$ was significantly higher in group 1 than in group 2 .
Within each group $\mathrm{FEV}_{1} / \mathrm{VC} \%$ improved significantly after immunotherapy ( $\mathrm{p}<0.0001$ for group 1 and $\mathrm{p}<$ 0.002 for group 2), but the degree of improvement was significantly greater in group 1 than in group 2 by ANOVA $(p=0.01)$. The mean of average increases in $\mathrm{FEV}_{1} /$ $\mathrm{VC}_{\mathrm{p}} \%$ per year by immunotherapy was significantly greater in group 1 than in group 2.

Because the mean age at the start of immunotherapy was significantly younger in group 1 than in group 2, it is most likely that the higher increases in $\mathrm{FEV}_{1} / \mathrm{VC}_{\mathrm{p}} \%$ in group 1 were due to the younger age of these patients.

In an attempt to minimize the age differences between patients of group 1 and 2, we selected only those patients who were 20 years old or younger at the time of the final $\mathrm{FEV}_{1}$ measurements for comparison between the two 


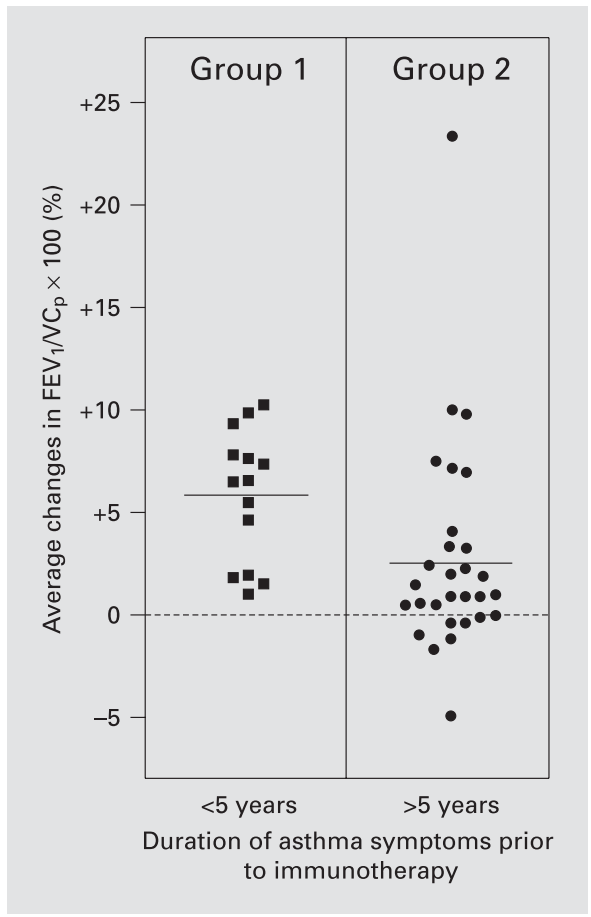

Fig. 4. Average changes in $\mathrm{FEV}_{1} / \mathrm{VC}_{\mathrm{p}} \times 100(\%)$ per year by immunotherapy are shown for the 14 patients in group 1 and for the 29 patients in group 2. groups. All 14 patients in group 1 were 20 years old or younger, ranging in age from 4 to 20 , but there were only 6 patients in group 2 who were 20 years old or younger, ranging in age from 6 to 20 during the study period. Despite the selection, the mean age of the 14 patients in group 1 was significantly younger than the mean age of the 6 patients in group 2 (table 3). There were no significant differences in the initial and final $\mathrm{FEV}_{1}$ and the changes in $\mathrm{FEV}_{1}$ before and after immunotherapy between the two groups. Therefore, at least in these small numbers of young patients, slight but significant differences in age and duration of asthma prior to immunotherapy did not result in significant differences in the $\mathrm{FEV}_{1}$ values between the two groups.

\section{Discussion}

Most of the controlled studies of AI proved their beneficial effects on allergic asthma due to a single allergen $[2,16]$. In the controlled trial of immunotherapy for asthma due to multiple allergens, injections of up to 7 allergens for over 2 years were of no discernible benefit in allergic children with perennial asthma [17]. Their patients
Table 2. Effect of immunotherapy on $\mathrm{FEV}_{1} / \mathrm{VC}_{\mathrm{p}} \times 100(\%)$
Table 3. Comparison of beneficial effects of immunotherapy on $\mathrm{FEV}_{1}$ between groups 1 and 2 in patients who were 20 years old or younger

\begin{tabular}{|c|c|c|c|}
\hline & \multicolumn{3}{|c|}{$\mathrm{FEV}_{1} / \mathrm{VC}_{\mathrm{p}} \times 100, \%$} \\
\hline & group 1 & group 2 & $\mathrm{p}$ values \\
\hline Before immunotherapy & $77.936 \pm 5.021$ & $79.228 \pm 3.468$ & 0.8330 \\
\hline After immunotherapy & $99.050 \pm 3.364$ & $87.941 \pm 2.945$ & 0.0272 \\
\hline $\begin{array}{l}\text { Average changes in } \mathrm{FEV}_{1} / \mathrm{VC}_{\mathrm{p}} \times 100 \\
\text { per year by immunotherapy }\end{array}$ & $5.879 \pm 0.856$ & $2.641 \pm 0.952$ & 0.0367 \\
\hline
\end{tabular}

Values represent mean \pm standard error of the mean.

\begin{tabular}{lccl}
\hline & Group 1 & Group 2 & p values \\
\hline Patients & 14 & 6 & \\
Age at initial $\mathrm{FEV}_{1}$, years & $7.2 \pm 0.87$ & $10.3 \pm 0.62$ & 0.039 \\
$\begin{array}{l}\text { Duration of asthma prior to immunotherapy, } \\
\quad \text { years }\end{array}$ & $2.64 \pm 0.17$ & $6.67 \pm 0.33$ & 0.0001 \\
Initial $\mathrm{FEV}_{1} / \mathrm{VC}_{\mathrm{p}} \times 100, \%$ & $77.94 \pm 5.02$ & $88.25 \pm 6.5$ & 0.257 \\
Final $\mathrm{FEV}_{1} / \mathrm{VC}_{\mathrm{p}} \times 100 \%$ & $99.05 \pm 3.36$ & $95.22 \pm 4.68$ & 0.531 \\
$\begin{array}{l}\text { Changes in } \mathrm{FEV}_{1} / \mathrm{VC}_{\mathrm{p}} \times 100 \text { before and after } \\
\quad \text { immunotherapy, } \%\end{array}$ & $5.88 \pm 0.86$ & $2.2 \pm 2.21$ & 0.0724 \\
\hline
\end{tabular}

Values represent mean \pm standard error of the mean. 
were selected for compliance during a long run-in period of observation and stabilization. Therefore, 'the participants in their study were not typical of allergic children treated for asthma in routine clinical practice' [17].

In the present study, we attempted to examine whether AI that we use routinely in our clinic is truly beneficial for every patient who improves in clinical symptoms as assessed by the criteria of the 1997 NIH guidelines. In order to substantiate the improvement in clinical symptoms objectively, we obtained $\mathrm{FEV}_{1}$ since a strong association exists between percent predicted $\mathrm{FEV}_{1}$ and the risk of an asthma attack over the subsequent year in a pediatric population [8]. Furthermore, we tried to evaluate whether the beneficial effects of successful immunotherapy are influenced by the duration of asthma prior to immunotherapy. An advantage of $\mathrm{FEV}_{1}$ as a marker of asthma severity is that it is frequently measured in routine clinical practice. Since improvements in $\mathrm{FEV}_{1}$ parallel improvements in other asthma outcomes such as exacerbations and quality of life [18], objective measures of lung function are necessary in the assessment of the risk for adverse asthma outcomes.

All 43 patients in this study had received our routine immunotherapy against their respective allergens and became asymptomatic. Although there was no significant correlation between the duration of asthma prior to immunotherapy and the changes in $\mathrm{FEV}_{1}$ before and after immunotherapy in all 43 patients, there was a significant correlation in 23 patients whose asthma duration was less than 20 years. It was also noted that all 14 patients whose asthma duration was less than 5 years prior to immunotherapy showed increases in $\mathrm{FEV}_{1}$ after immunotherapy. Accordingly, the 43 patients were divided into two groups depending on the duration of asthma symptoms prior to immunotherapy. A beneficial effect of immunotherapy on $\mathrm{FEV}_{1}$ was greater in group 1 who were younger and began immunotherapy less than 5 years after the onset of the first asthma symptoms.

Currently, AI is considered to be indicated when avoidance of allergens and symptomatic medications fail to relieve allergy symptoms satisfactorily. In a patient with child-onset atopic asthma, it may take several years for a trial of symptomatic medications to be fully evaluated. A belief by some people that childhood asthma may spontaneously remit might further delay a decision to start immunotherapy. As an early intervention ICS have been well documented to be effective. However, when ICS are discontinued $\mathrm{FEV}_{1}$ decreases and asthma exacerbates [13]. In group 1, 8 of 14 patients (57\%) discontinued ICS when they became asymptomatic since their
$\mathrm{FEV}_{1} / \mathrm{VC}_{\mathrm{p}}$ exceeded $100 \%$ whereas only 9 of 29 patients $(31 \%)$ of group 2 could discontinue ICS. However, we cannot exclude the potential beneficial effects of early intervention with ICS in group 1 in addition to the beneficial effects of early intervention with AI.

In order to achieve and maintain a higher $\mathrm{FEV}_{1}$ it may be necessary to start immunotherapy as soon as asthma symptoms appear before irreversible structural changes begin in the airways. Although we could not ascribe the beneficial effects of immunotherapy on $\mathrm{FEV}_{1}$ to the shorter duration of asthma prior to immunotherapy in our patients of group 1, an early intervention in patients with child-onset asthma means, by necessity, starting the intervention at young ages. This approach is in keeping with the ARIA (Allergic Rhinitis and Its Impact on Asthma) concept of preventing asthma in patients with allergic rhinitis $[4,6]$. Immunotherapy should be considered in patients with child-onset atopic asthma at the earliest possible stage of disease since a greater improvement in $\mathrm{FEV}_{1}$ is more likely to occur if immunotherapy is introduced when they are younger and sooner after the onset of asthma symptoms.

\section{Acknowledgments}

We thank Marie Nagaya, PhD and Mrs. Reiko Nagaya for excellent editorial and secretarial assistance. 


\section{References}

1 Bousquet J, Lockey RF, Malling HJ: Allergen immunotherapy: therapeutic vaccines for allergic diseases. A WHO position paper. J Allergy Clin Immunol 1998;102:558-562.

2 Abramson MJ, Puy RM, Weiner JM: Is allergen immunotherapy effective in asthma? A meta-analysis of randomized controlled trials. Am J Respir Crit Care Med 1995;151:969_ 974.

3 Norman PS: Immunotherapy: past and present. J Allergy Clin Immunol 1998;102:1-10.

- 4 Moller C, Dreborg S, Ferdousi HA, Halken S, Host A, Jacobsen L, Koivikko A, Koller DY, Niggemann B, Norberg LA, Urbanek R, Valovirta E, Wahn U: Pollen immunotherapy reduces the development of asthma in children with seasonal rhinoconjunctivitis (the PATStudy). J Allergy Clin Immunol 2002;109: 251-256.

5 National Asthma Education and Prevention Program, Clinical Practice Guidelines. Expert Panel Report 2: Guidelines for the diagnosis and management of asthma. Bethesda, National Institutes of Health/National Heart, Lung and Blood Institute, 1997, NIH Publication No. 97-4051.

- 6 Bousquet J, van Cauwenberge P, Khaltaev N; ARIA Workshop Group: Allergic rhinitis and its impact on asthma. J Allergy Clin Immunol 2001;108:S147-S336.
7 Vaughan TR, Weber RW, Tipton WR, Nelson HS: Comparison of PEFR and $\mathrm{FEV}_{1}$ in patients with varying degrees of airway obstruction. Effect of modest altitude. Chest 1989;95: 558-562.

8 Fuhlbrigge AL, Kitch BT, Paltiel AD, Kuntz KM, Neumann PJ, Dockery DW, Weiss ST: $\mathrm{FEV}_{1}$ is associated with risk of asthma attacks in a pediatric population. $\mathrm{J}$ Allergy Clin Immunol 2001;107:61-67.

9 Agertoft L, Pedersen S: Effects of long-term treatment with an inhaled corticosteroid on growth and pulmonary function in asthmatic children. Respir Med 1994;88:373-381.

10 Selroos O, Pietinalho A, Lofroos A-B, Riska H: Effect of early vs. late intervention with inhaled corticoids in asthma. Chest 1995;108: 1228-1234.

11 O'Byrne PM, Pedersen S: Measuring efficacy and safety of different inhaled corticosteroid preparations. J Allergy Clin Immunol 1998; 102:879-886.

12 Scott MB, Skoner DP: Short-term and longterm safety of budesonide inhalation suspension in infants and young children with persistent asthma. J Allergy Clin Immunol 1999;104: S200-S209.
13 Haahtela T, Jarvinen M, Kava T, Kiviranata K, Koskinen S, Lehtonen K, Nikander K, Persson T, Selroos O, Sovijarvi A, Stenius-Aarniala B, Svahn T, Tammivaara R, Laitinen LA Effects of reducing or discontinuing inhaled budesonide in patients with mild asthma. $\mathrm{N}$ Engl J Med 1994;331:700-705.

14 Reddy MP, Nagaya H, Pascual HC, Lee SK, Gupta S, Lauridsen JI, Jerome DC: Reappraisal of intracutaneous tests in the diagnosis of reaginic allergy. J Allergy Clin Immunol 1978; 61:36-41.

15 Lockey RF, Bukantz SC: Allergens and Allergen Immunotherapy, ed 2. New York, Marcel Dekker, 1999.

16 Bousquet J, Michel F-B: Specific immunotherapy in asthma: is it effective? J Allergy Clin Immunol 1994;94:1-11.

17 Adkinson NF, Eggleston PA, Eney D, Goldstein EO, Schuberth KC, Bacon JR, Hamilton RG, Weiss ME, Arshad H, Meinert CL, Tonascia J, Wheeler B: A controlled trial of immunotherapy for asthma in allergic children. N Engl J Med 1997;336:324-331.

18 Noonan M, Chervinsky PP, Busse W, Weisberg S, Pinnas J, de Boisblanc B, Boltansky $\mathrm{H}$, Pearlman D, Repsher L, Kellerman D: Fluticasone propionate reduces oral prednisone use while it improves asthma control and quality of life. Am J Respir Crit Care Med 1995; 152 1467-1473. 